\title{
PERANCANGAN GEDUNG SEKOLAH TAHAN GEMPA DI CABANG MUHAMMADIYAH WEDI KLATEN
}

\section{Sri Widodo, M.S.Priyono Nugroho, dan Budi Setiawan \\ Fakultas Teknik \\ Universitas Muhammadiyah Surakarta}

\section{ABSTRACT}

Earthquake effect at 27 May 2006 have destroyed buildings of Muhammadiyah effort in Wedi Klaten. The damages of buildings are cover: (a) TK ABA I and II have damages of roof and wall; (b) TK Islam terpadu, children play group have total damage; (c) SD Islam terpadu have light damage. The damages of shool building have pursued the process of education at the school. In order to aim recovery the damages school, activity of this devotion to society is to give design of school building which earthquake resitance, cheap, quickly construction and can be developed. School building designed to one class unit, so that if needed some classes remain to combine it, and this combining is accomodated with area and shape of land available. Designing by using system of earthquake resistance. The concepts are as light as possible and the and the building framework which consist of column, ring beam and sloof beam are made interaction so that forming room construction that having bigger moment of inertia. The activity of devotion to society have produced design of one class unit with size $6 \mathrm{~m} \times 8 \mathrm{~m}$ with building framework consist of reinforced concrete, wall from wood and roof made from waving zinc. One class unit is estimated require Rp.13,796,213.of construction cost with duration of constructon is one month.

Keyword: earthquake, school building, earthquake resistance, cheap, quickly.

\section{PENDAHULUAN}

Gempa bumi hari Sabtu tanggal 27 Mei 2006 sekitar jam 6 pagi yang berkekuatan 5,9 Skala Richter telah merusak gedung-gedung amal usaha Muhammadiyah yang ada di Wedi Klaten. Gedung-gedung yang rusak tersebut meliputi: (a) TK ABA I dan II mengalami kerusakan dinding dan atap; (b) TK 
Islam terpadu, tempat penitipan anak dan kelompok bermain mengalami rusak total; (c) SD Islam terpadu mengalami rusak ringan. Kerusakan gedung-gedung tersebut telah menghambat jalannya pendidikan yang ada di sekolah tersebut. Untuk sementara kegiatan belajar mengajar dilaksanakan di tenda-tenda darurat yang tentu kondisinya tidak memenuhi persyaratan sebagai prasarana belajar mengajar.

Berdasar pengamatan di lokasi bencana, kerusakan - kerusakan gedung sekolah diakibatkan tidak adanya angkur pengikat antara kolom dengan dinding serta tidak adanya kesatuan yang kuat antara struktur bangunan yang berfungsi untuk menyatukan semua struktur bangunan agar bekerja secara bersama-sama sebagai satu kesatuan. Selain itu juga konstruksi dinding bata dan atap genteng yang relatif berat menyebabkan gaya akibat gempa bumi yang menimpa bangunan semakin besar pula, padahal bangunan-bangunan yang ada tidak dirancang menahan gaya gempa .

Melihat permasalahan yang ada di lokasi bencana, maka perlu adanya perancangan gedung sekolah yang murah, mudah dilaksanakan dan mudah dikembangkan. Konsep bangunan murah dengan dana terbatas gedung tersebut dapat segera mulai dibangun. Konsep mudah dilaksanakan dengan harapan tidak memerlukan keahlian khusus dan cepat pelaksanaannya menggunakan tenaga kerja setempat. Konsep mudah dikembangkan dengan harapan saat kekuatan ekonomi kembali menguat bangunan ini mudah dikembangkan sesuai dengan kebutuhan. Permasalahan lainnya adalah tidak adanya ahli bangunan yang ada di Majlis Dikdasmen Aisyiyah Wedi Klaten, sehingga dalam merancang kembali gedung sekolah yang tahan gempa, aman, murah dan segera dapat digunakan mengalami kesulitan.

Tujuan kegiatan ini adalah memberikan rancangan bangunan sekolah tahan gempa yang murah dan dapat segera dipakai tetapi tidak menutup kemungkinan untuk dikembangkan jika tersedia dana yang mencukupi. Hal ini penting dilakukan agar kegiatan belajar mengajar secara pelan-pelan bisa pulih kembali dan dapat berjalan dengan normal.

Kegiatan ini diharapkan akan memberikan manfaat bagi Majlis Dikdasmen Aisyiyah Wedi Klaten, karena gambar rencana bangunan sekolah beserta perkiraan biayanya dapat dipergunakan sebagai bekal mencari dana pembangunan. Dengan segera dibangunnya gedung sekolah yang rusak memberi kepercayaan kepada masyarakat yang menyekolahkan anaknya di sekolah

54 WARTA, Vol .10, No. 1, Maret 2007: 53 - 61 
Aisyiyah Wedi Klaten. Selain itu para siswa juga bisa belajar lagi secara normal sehingga kegitaan belajarnya tidak terganggu

Rumah di Pulau Jawa umumnya menggunakan bahan dinding yang terdiri dari pasangan bata atau conblock ditambah adukan semen dan pasir sebagai pengikatnya. Padahal, bata polos merupakan bahan bangunan yang sangat buruk daya tahannya terhadap beban gempa. Bata itu masif dan berat tetapi regas dan mudah roboh, karena itu tidak cocok untuk bangunan di daerah rawan gempa. Tetapi bahan bangunan itu akan menjadi sangat bagus dan kuat daya tahannya terhadap beban gempa bila diperkuat baja tulangan dengan cara yang benar atau dengan tiang balok pengekang (Siddiq, 2005).

Untuk rumah tinggal tembokan sederhana, kunci ketahanan gempa adalah pemakaian balok fondasi (sloof), kolom praktis, dan ring balok yang dibuat dari beton bertulang dan disatukan dengan pasangan batanya. Kunci kedua adalah dengan memakai atap yang relatif ringan dan terikat dengan baik pada konstruksi atapnya. Rumah tradisional Sumatera Barat dengan atap sengnya dan Bali dengan atap alang-alangnya menunjukkan kearifan nenek moyang kita, hal mana seharusnya diteruskan ke generasi saat ini. Kedua daerah rawan gempa ini telah memilih jenis atap yang sesuai sehingga tidak mengakibatkan gaya inersia yang besar saat terjadi gempa.

Untuk gedung-gedung konstruksi beton, kunci keberhasilannya dalam menahan gempa terletak pada dua hal, yaitu menaruh kait sengkang yang cukup dengan ujung yang cukup panjang dan ditekuk 135 derajat dan membuat tiang kolom beton lebih kuat daripada baloknya. Di Jakarta hal ini sudah banyak diterapkan sehingga umumnya bangunan gedung bertingkat di Jakarta diyakini mampu bertahan bila terjadi gempa yang besar (Sukamta, 2006).

Hasil peninjauan pakar bangunan tahan gempa dan pendiri Asosiasi Ahli Gempa Indonesia, Teddy Boen ke Nabire Papua pasca gempa di daerah itu menunjukkan bahwa rumah yang rusak akibat gempa hanya 45 persen. Kebanyakan rumah tembok yang tidak memenuhi teknis konstruksi. Sedangkan yang tidak mengalami kerusakan justru rumah tradisional dari kayu. Kondisi serupa dijumpai hampir di semua wilayah di Indonesia yang dilanda gempa hebat, termasukAlor, Nusa Tenggara Timur. Ini menunjukkan rumah tradisional sebagai warisan intelektual nenek moyang lebih teruji. (Kurniawan,2004)

Walaupun gempa tidak dapat kita prediksi, namun dapat diminimalisir dampak yang ditimbulkannya dengan cara membangun rumah tahan gempa. Ketika gempa dan tsunami melanda Aceh tahun 2004 lalu, sebagian besar rumah

Perancangan Gedung ... (Sri Widodo, dkk.) 55 
tradisional (berbahan kayu) masih tetap berdiri kokoh. Bahkan di negara jepang yang sering terjadi ratusan gempa, bahan dasar rumah mereka terbuat dari kayu dan kertas (Rusmawan, 2005)

Beberapa persyaratan bangunan tahan gempa adalah harus ringan, dan fondasi harus diikat kaku dengan menggunakan balok fondasi. Pada setiap luasan dinding $12 \mathrm{~m} 2$, harus dipasang kolom, dapat menggunakan bahan kayu, beton bertulang, baja, pilaster ataupun bambu. Dan kolom diikat kaku dengan balok fondasi. Jika ditempatkan di daerah gempa kecil, tidak akan merusak struktur dan bangunan, jika di tempat gempa sedang bangunan mungkin retak, tapi struktur tetap kokoh, dan jika ditempatkan di daerah gempa kuat, bangunan bisa jadi rusak, tapi struktur tetap kokoh berdiri (Sabaruddin, 2003).

\section{METODE PELAKSANAAN}

Untuk memecahkan masalah yang dihadapi Majlis Dikdasmen Aisyiyah Wedi Klaten adalah dengan cara menyediakan rancangan bangunan sekolah yang tahan gempa, dengan sistem konstruksi bertahap sehingga pelaksanaannya bisa disesuaikan dengan biaya yang tersedia. Rancangan bangunan juga dilengkapi dengan rencana anggaran biaya yang meliputi jenis dan volume pekerjaan yang harus diulaksanakan serta harga satuan dari masing-masing jenis pekerjaan tersebut. Dengan mengalikan volume pekerjaan dan harga satuan pekerjaan diperoleh jumlah biaya yang diperlukan untuk membangun satu unit sekolah. Agar Majlis Dikdasmen Aisyiyah Wedi Klaten betul-betul memahami rancangan bangunan tersebut diadakan penjelasan mengenai rancangan bangunan sekolah yang akan dibuat dan gambaran teknis pelaksanaan pembangunan

Dengan adaya rancangan bangunan sekolah yang detail diharapkan akan dapat menjadi acuan dalam membangun kembali prasarana gedung sekolah yang rusak akibat gempa bumi. Pembangunan kembali gedung sekolah yang rusak juga memberikan citra yang baik kepada Aisyiyah Wedi. Selain itu gedung sekolah yang dibangun diharapkan juga bisa menjadi percontohan bagi penduduk Wedi lainnya yang rumahnya roboh karena gempa, untuk membangun kembali rumahnya dengan model seperti gedung sekolah Aisyiyah yang akan dibangun.

\section{HASIL PENGABDIAN DAN PEMBAHASAN}

Hasil dari kegiatan pengabdian ini adalah gambar rencana tipikal satu unit klas yang terdiri dari gambar denah seperti pada Gambar 1 dan gambar perspektif bangunan sekolah yang berukuran $6 \mathrm{~m}$ x $8 \mathrm{~m}$ seperti pada Gambar

56 WARTA, Vol .10, No. 1, Maret 2007: 53 - 61 
2. Klas ini diharapkan mampu menampung 42 siswa murid.Jika ingin dibangun beberapa klas sesuai dengan siswa yang ada, maka kelas-kelas lainnya tinggal menggandeng baik secara memanjang atau melebar sesuai dengan bentuk lahan yang tersedia.

Bangunan dirancang dengan fondasi plat beton bertulang ukuran $60 \mathrm{~cm}$ $\mathrm{x} 60 \mathrm{~cm}$ dengan ketebalan $20 \mathrm{~cm}$. Sebagai penyangga atap dan sekaligus sebagai pengaku dinding digunakan kolom beton bertulang ukuran $20 \mathrm{~cm} \times 20 \mathrm{~cm}$ dengan tulangan 4 diameter $6 \mathrm{~mm}$. Untuk mempersatukan kolom agar bekerja secara bersama-sama dalam satu sistem bangunan saat menghadapi gaya luar (gempa) maka pada bagian bawah dan atas kolom dihubungkan dengan balok beton ukuran $15 \mathrm{~cm}$ x $20 \mathrm{~cm}$ yang diperkuat dengan tulang baja 4 diameter $6 \mathrm{~mm}$.

Dinding terbuat dari papan kayu sengon tebal $2 \mathrm{~cm}$ setinggi 1,5 m yang diperkuat dengan rangka kayu ukuran $4 \mathrm{~cm}$ x $6 \mathrm{~cm}$.. Kosen dan daun pintu terbuat dari kayu Akasia. Rangka atap terbuat dari kayu Glugu dengan penutup dari seng gelombang yang ringan dan rapat sehingga tidak mudah bocor. Dengan ketinggian dinding yang hanya 1,5 m diharapkan aliran udara sangat lancar sehingga walaupun atap terbuat dari seng tetapi udara dalam kelas tetap tidak panas sehingga suasana belajar akan nyaman.Lantai terbuat dari beton rabat tebal $4 \mathrm{~cm}$ sehingga kondisi cukup kuat dan tidak mudah rusak.

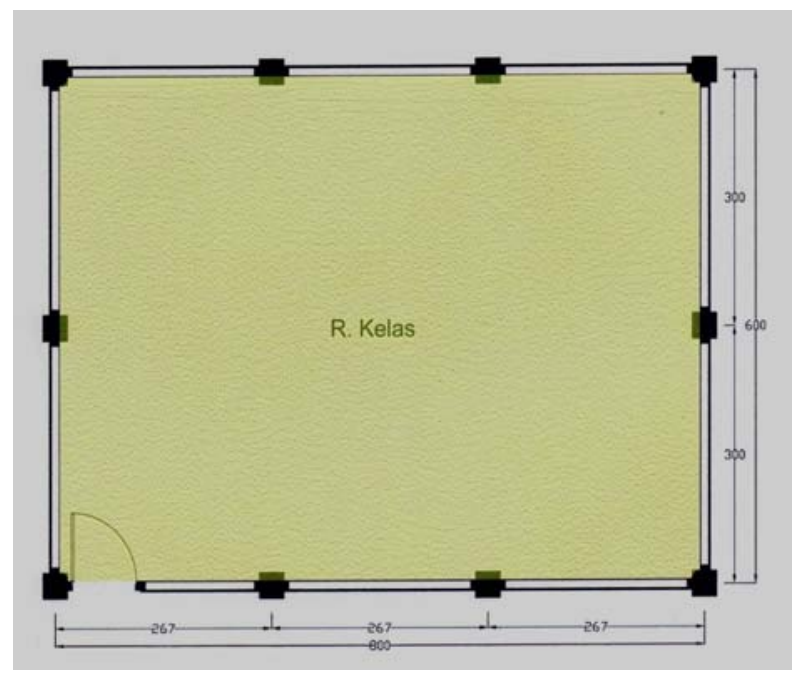

Gambar 1 : Denah satu unit ruang kelas

Perancangan Gedung ... (Sri Widodo, dkk.) 57 

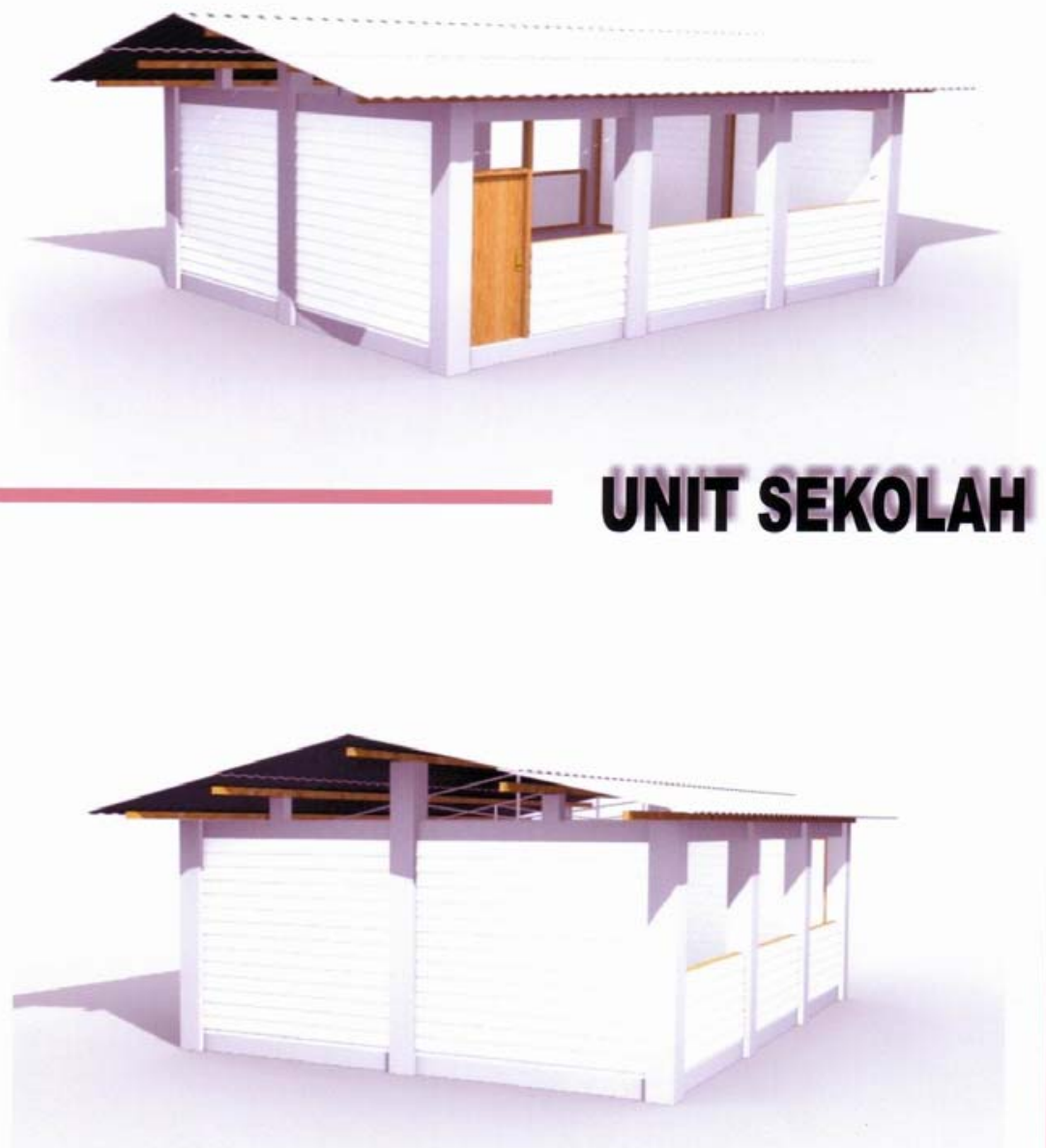

Gambar 2 : Perspektif bangunan kelas

58 WARTA, Vol .10, No. 1, Maret 2007: 53 - 61 
Untuk membuat ruangan klas seperti dalam gambar rencana tersebut diatas dibutuhkan waktu kira-kira 1 bulan dengan biaya Rp.13.796.213,-dengan perincian seperti pada Tabel 1. Harga-harga bahan bangunan adalah berdasar informasi yang diperoleh dari Toko Bahan bangunan yang ada di Kartasura. Demikian pula upah tenaga kerja juga seperti yang berlaku di daerah Kartasura.

Tabel 1.

Rencana Anggaran Biaya Satu Unit Kelas

\begin{tabular}{|c|c|c|c|c|c|}
\hline No & Uraian Pekerjaan & Volume & $\begin{array}{c}\text { Harga satuan } \\
\text { pekerjaan } \\
\end{array}$ & \multicolumn{2}{|c|}{ Jumlah harga } \\
\hline 1 & Galian tanah & $2,4 \mathrm{~m} 3$ & Rp 19.750 & $\mathrm{Rp}$ & 47.400 \\
\hline 2 & Urugan tanah kembali & $1,2 \mathrm{~m} 3$ & 7.900 & $\mathrm{Rp}$ & 9.480 \\
\hline 3 & Urugan tanah + pemadatan & $8 \mathrm{~m} 3$ & 50.500 & Rp & 404.000 \\
\hline 4 & Urugan pasir bawah pondasi & $0,2 \mathrm{~m} 3$ & $\mathrm{Rp} \quad 56.300$ & $\mathrm{Rp}$ & 11.260 \\
\hline 5 & Pek. Beton bertulang 1:2:3 & $4 \mathrm{~m} 3$ & Rp 1.180.620 & $\mathrm{Rp}$ & 4.722 .480 \\
\hline 6 & Lantai rabat beton tebal $4 \mathrm{~cm} \mathrm{1:3:6}$ & $48 \mathrm{~m} 2$ & $\mathrm{Rp} \quad 21.736$ & Rp & 1.043.328 \\
\hline 7 & Rangka dinding kayu & $0,6 \mathrm{~m} 3$ & Rp 1.260 .500 & $\mathrm{Rp}$ & 756.300 \\
\hline 8 & Pek. Rangka Kuda-kuda & $0,7 \mathrm{~m} 3$ & Rp 3.117.500 & $\mathrm{Rp}$ & 2.182 .250 \\
\hline 9 & Pek. Dinding papan & $56 \mathrm{~m} 2$ & Rp $\quad 26.625$ & $\mathrm{Rp}$ & 1.491 .000 \\
\hline 12 & Pek. Gording & $0,33 \mathrm{~m} 3$ & Rp 2.360.500 & $\mathrm{Rp}$ & 778.965 \\
\hline 13 & Pek. Penutup Atap seng & $80 \mathrm{~m} 2$ & 22.425 & Rp & 1.794 .000 \\
\hline 14 & Pek. Bubungan Atap Seng & $10 \mathrm{~m}^{\prime}$ & 25.575 & $\mathrm{Rp}$ & 255.750 \\
\hline 16 & Pintu Kayu Akasia + Kosen & 1 bh & Rp $\quad 300.000$ & $\mathrm{Rp}$ & 300.000 \\
\hline & Jumlah Total Harga & & & $R p$ & 3.796 .213 \\
\hline
\end{tabular}

Rancangan bangunan klas ini sengaja menggunakan dinding dari kayu dan atap seng dengan harapan akan diperoleh bangunan yang ringan dan cepat pengerjaan. Konsep bangunan ringan dengan maksud agar jika ada gempa bumi gaya gempa bumi yang bekerja pada bangunan tersebut kecil, 
karena gaya gempa bumi merupakan fungsi dari berat bangunan. Dengan kecilnya gaya gempa bumi diharapkan mampu ditahan oleh struktur bangunan yang ada.

Rangka bangunan yang terdiri dari kolom, balok sloof dan balok ring semuanya terbuat dari beton bertulang yang saling berhubungan sehingga membentuk konstruksi ruang. Konstruksi ruang ini mempunyai momen inersia yang besar sehingga lebih kuat menahan momen guling akibat adanya gaya horisontal yang ditimbulkan oleh gempa. Sementara gaya vertikal akibat berat sendiri bangunan yang sebagian besar terbuat dari kayu dan seng relatif ringan sehingga cukup kuat ditahan oleh rangka bangunan yang relatif tidak berdimensi besar.

Pembuatan rangka bangunan dari beton bertulang ini dengan maksud, suatu saat sudah tersedia dana yang memadai, maka secara perlahan-lahan dinding kayu bisa dirubah dengan dinding batu bata seperti pada umumnya sehingga unsur keindahan akan tercapai. Untuk meyakinkan bahwa rancangan sekolah ini cukup layak untuk sarana belajar, diperlukan sosialisasi yang baik. Akan tetapi mengingat kejadian gempa yang sangat fatal akibatnya terhadap bangunan dan manusia, maka faktor keselamatan seharusnya lebih diutamakan daripada faktor-faktor lainnya. Maka bangunan tahan gempa yang murah menjadi alternatif terbaik untuk membangun kembali kawasan korban gempa bumi.

\section{SIMPULAN DAN SARAN}

Mengingat bangunan sekolah sebagai prasarana belajar siswa perlu segera dibangun kembali agar kegiatan belajar mengajar tidak berhenti maka rancangan bangunan sekolah harus mempunyai konsep :

1. Cepat pelaksanaannya dengan biaya murah tetapi tahan terhadap gempa. Faktor-faktor lain yang tidak sesuai dengan ketiga konsep tersebut untuk sementara harus diabaikan terlebih dahulu.

2. Mempunyai konsep siap tumbuh, sehingga suatu saat dana tersedia untuk meningkatkan kualitas bangunan, tidak perlu merusak atau meninggalkan bangunan yang sudah ada.

Agar program pemulihan kembali kegiatan belajar mengajar yang sempat terganggu akibat adanya gempa bumi maka diperlukan langkah-langkah sebagai berikut:

1. Perlu adanya kerjasama yang baik antara pihak-pihak yang berkompenten terhadap pemulihan kembali daerah korban bencana dengan masyarakat korban bencana.

60 WARTA, Vol .10, No. 1, Maret 2007: 53 - 61 
2. Perlu bimbingan atau pendampingan dari pihak yang ahli dibidang bangunan jika program berkaitan dengan pembuatan suatu bangunan.

3. Semangat masyarakat korban bencana perlu dhidupkan lagi dengan program-program yang nyata yang akan membawa kehidupan yang lebih baik.

\section{DAFTAR PUSTAKA}

Kurniawan. 2004. “Tinggalkan Rumah Batu, Kembali ke Kayu”. Internet.

Munandar, M. 2001. “Ketentuan Dinding Tembok Wilayah Gempa”. Buletin Pengawasan No. 30.

Siddiq, S. 2005. "Untuk Keselamatan Jiwa dan Raga Perlu Konstruksi Tahan Gempa”. Internet

Sukamta, D. 2006. "Bangunan Tahan Gempa". Internet

Rusmawan, D. 2005. “Konsep Rumah Tahan Gempa”. Internet

Sabaruddin, A. 2003. "Risha, Rumah Sederhana Tahan Gempa”. Internet 
62 WARTA, Vol .10, No. 1, Maret 2007: 53 - 61 
Perancangan Gedung ... (Sri Widodo, dkk.) 63 